\title{
THE RESEARCH OF THE AdJUSTABLE ELECTRIC DRIVE OF THE DIRECT CURRENT
}

\author{
BREIDO, I.; KAVERIN, V. \& EM, G.
}

Abstract: As a result of the executed researches of the generating modes of the thyristor electric drive for the ground ropeways, winches of drilling rigs and other equipment with the sign-variable moment of loading was determined that the mode of recuperative braking could be realized only in case of great and average values of the electromotor speed in difference from the electric drive of a direct current in case of power supply from an ideal source of a direct current. The technical solution which excludes unstable operation modes in the countercurrent mode at small speeds was offered and it automatically provides a choice of the necessary generating mode of a recuperation or a countercurrent. Theoretical researches of the emergency braking modes connected to blackout, the need of implementation of which is caused by safety regulations which impose strict requirements to the brake way length of the main mining equipment were executed. The technical solution on the basis of the dynamic braking system with the shunting diode connected parallel to the engine drive winding is developed that allows to use the energy accumulated in the drive winding for implementation of the mode of emergency braking.

Key words: thyristor electric drive, a sign-variable moment of loading, generating modes, emergency braking
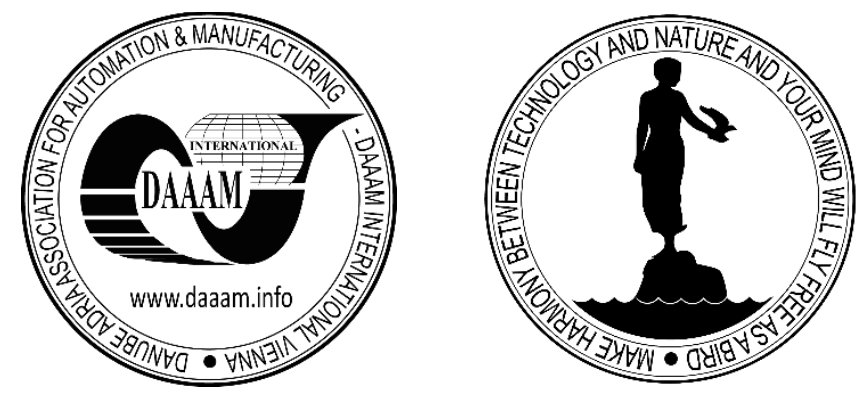

Authors' data: Prof., Dr. of Techn.Sc. Breido, I[osif]*; Ass.Prof., Cand. of Techn.Sc. Kaverin, V[ladimir]**, Mast. of Techn.Sc. Em, G[ennadiy]***, Karaganda State Technical University, Boulevard in the World 56, Karaganda, Kazakhstan,jbreido@mail.ru, egaapp@mail.ru

This Publication has to be referred as: Breido, I[osif]; Kaverin, V[ladimir] \& Em, G[ennadiy] (2018). The Research of the Adjustable Electric Drive of the Direct Current, Chapter 19 in DAAAM International Scientific Book 2018, pp.211-226, B. Katalinic (Ed.), Published by DAAAM International, ISBN 978-3-902734-19-8, ISSN 1726-9687, Vienna, Austria

DOI: 10.2507/daaam.scibook.2018.19 
Breido, I.; Kaverin, V. \& Em, G.: The Research of the Adjustable Electric Drive of ...

\section{Introduction}

Good adjusting properties, rigidity of mechanical characteristics, wide range of speeds in the modes of constant power and a possibility of providing the constant moment in this range of speeds, existence of 4-quadrant operating modes with energy recovery have caused distribution of thyristor electric drives of a direct current (TED DC) in various industries, including the mining. It is connected with such features of the electric drive of a direct current as his high reloading ability, possibility of work on an emphasis, independence of the maximum moment of the electric motor of a direct current of power failure in network of power supply in the modes of heavy start-up that is the main reasons for use such electric drives for the mining equipment (Breido, 1993).

Both motive and generating operating modes are implemented in use of the specified classes of mining machines and mechanisms.

The theoretical and practical problems connected with a research of fourquadrant TED DC in the motive and short-term generating modes were investigated rather deeply (Breido \& Em, 2011; Subramanyam, 1987; Sen, 1981).

A number of technological machines and mechanisms, such as ground ropeways and winches of drilling rigs, requires management of electric drive parameters in generating operating modes at the sign-variable moment of resistance forces. And the operated generating modes of technological braking for such cars have long character, in communication by need of long control of the electric drive with the sign-variable moment of loading (Breido, 1993).

At the same time, it is necessary to provide repeated steady transitions from motive to the generating modes and back with acceptable indicators (Em, 2013).

However, in the known developments, dynamic properties and features of fourquadrant TED DC in controlled generating operation modes including the transition from a mode to a mode and also in the motive modes in the conditions of the lowpower network, typical for mining with remote sources of electrical power supply were not considered sufficiently. It is necessary to refer the determination of the real range of existence of the mode of recuperative braking on speeds, specification of work areas of the modes of a recuperation and countercurrent taking into account impulse character of tension of the rectifier as unresolved issues.

Until recently the most acceptable basic option of the emergency modes implementation and technological braking in the electric drive of a direct current speed was the method of dynamic braking with independent energization. However, the rupture of a force circuit arising after blackout does not allow to realize this principle of control in the modes of emergency braking.

The research aims are:

- definition of real borders of existence of the generating modes with recovery of energy taking into account impulse type of work of the thyristor converter;

- research and development of the technical solutions providing effective braking in the electric drive adjusted on speed at emergency shutdown of the electric power. 


\section{A research of the characteristics of the electric drive in the generating modes}

Basic feature of the force diagram of the gated transformer as link of the regulation system is that even in case of a persistence of its parameters it cannot be described in general as the linear link as in the course of operation of the transformer, there is a serial switching of load current from one phase to another. It is necessary to mark that in the modes of overloads and in case of emergency processes, the bigger number of phases also can be involved in process of switching.

In the course of switching of the transformer there is an intermittent change of its parameters.

Similar intermittent change of parameters happens also in the mode of intermittent currents of the transformer. Here the intervals of a zero current connected to gated conductivity and impulse operation of the transformer take place.

Thus, the force diagram and impulse kind of work of the thyristor transformer contribute the additional specifics and exert the considerable impact on direct and response characteristics of the electric drive in general (Em \& Breido, 2012; Breido et al., 2013).

It is known, that in the electric drive of the machines and mechanisms allowing to realize controlled braking in the technological modes, three possible methods of electric braking: countercurrent, dynamic and recuperative braking are used (Daware, 2014).

Most widely, despite the considerable losses of energy in current limiting resistors, in connection with the relative simplicity of technical solutions, the dynamic braking is applied. The systems of dynamic braking provide effective braking, close to nominal, at the same time in electric drives of load-lifting machines and mechanisms where the required control range of speed changes from 1:10 to $1: 100$, this method in the lower part of the range for obtaining steady creeping speeds is ineffective.

In electric drives of the ground ropeways components of the moments of the resistance forces connected to gravity have the active character and depending on an area profile on which the load moves, they can change signs, and this process can be repeated. In electric drives of the load-lifting haulers of drilling rigs during descent of a drilling column, resistance moment component, connected to gravity can exceed the component caused by frictional force about slit walls, then the summary moment of resistance forces promotes movement, also the opposite situation with repetition is possible.

At the same time, it is necessary to provide repeated steady transitions from motive to the generating modes and back. Support of acceptable accuracy of the speed stabilizing and satisfactory response characteristics of the electric drive is very problematic when using systems of dynamic braking in these conditions.

More effective is generating braking with recuperation energies in a network (Bhadra et al., 2017; Rashid, 2017). The traditional diagram of the double electric drive of a direct current providing recuperative braking contains the two-complete thyristor transformer in an anchor circuit, and the reverse is carried out on an anchor circuit. At the same time transition of the drive from the motive mode in generating is 
executed by transfer of the transformer to an inverter operation mode with the subsequent reversing. However, practical use of the recuperative mode encounters a row of technical difficulties. So, to unresolved questions of application of recuperative braking, there is a determination of the real range of existence of this mode depending on electric drive speed. The key part of the issue is that in connection with one-sided conductivity of a valve and impulse form of tension on the controlled rectifier output, the mode of recuperative braking can be realized in that interval of time when the EMF amplitude value of the engine exceeds the EMF amplitude value of a source of the electric power on the module. Meanwhile, in the analysis of the mode of recuperative braking in thyristor electric drives, as a rule, it is not amplitude, but effective or average value of EMF source. Therefore, the mode of recuperative braking can be realized in narrower range of changing parameters of the electric drive than in the electric drive of a direct current with a supply from a source of a direct current, for example from direct current network.

In case of small frequency rates of the engine rotation in a recuperative operation mode, EMF amplitude value of an anchor is much less than EMF amplitude value of a power source. In this case it is almost impossible to develop the brake moment of the sufficient value. In other words, in the drive where the deep of regulation on speed is necessary, implementation of the maximum brake moment in case of small values of angular speed is not possible as internal resistance of the engine and power supply do not allow to provide the anchor circuit current necessary for development of the maximum value of the moment.

At the same time at the smallest speeds the generating mode of a countercurrent is of interest as in this EMF mode of a source of the electric power and EMF of the electromotor are added.

In the countercurrent mode in case of the EMFs small values of the thyristor transformer it is possible to receive the continuous current at the expense of the EMF of the engine and to develop the brake moment sufficient for maintenance of stable speed. Besides, on technological operating conditions of the considered machines and mechanisms, the reverse which is also realized in the countercurrent mode is necessary.

With a research objective of features of the generating modes of a countercurrent and a recuperation, determination of work areas of their application and detection of optimum boundaries of transition from one mode to another in a software environment of MatLab-Simulink the simulation model was developed (Em \& Breido, 2012).

In a simulation model the generating modes caused by existence of the positive untwisting moment typical for load-lifting installations, and a negative brake moment of the electrical machine are realized.

Simulation modeling was carried out on the example of the direct current motors which gained distribution in the former Soviet Union with independent energization of a series $4 \mathrm{PF}$ of average power of Russian production.

Because the vast majority of serially released complexes of TED DC it does not assume existence of current limiting resistors in an anchor circuit, the analysis of the 
generating modes and their characteristics without current-limiting resistance was carried out in operation

As a result of the experiments made in the recuperative mode there were three families of mechanical characteristics for engines 4PF132L, 4PF160L and 4PF180L in case of changing an angle of control of inverter group thyristors from $90^{\circ}$ to $140^{\circ}$. In the course of simulation, the untwisting moment changed in the range from 0 to rated $\mathrm{M}_{\mathrm{n}}$ value corresponding to each type of the electrical machine.

During the imitative experiments three families of mechanical characteristics of TED DC in the countercurrent mode in the absence of current limiting resistors in an anchor circuit for the second quadrant of mechanical characteristics were also received. In a simulation model the countercurrent mode with a reverse on an anchor winding circuit was realized. The two-complete (reverse) thyristor transformer in which the considered process is provided by switching from a direct thyristor set on reverse and also the job of the appropriate control angle of thyristors and the sign of the untwisting moment was used for this purpose. In this case the control angle of thyristors changed in the range $90^{\circ} \div 120^{\circ}$. In a figure 1 mechanical characteristics corresponding to the countercurrent mode, for the purpose of detection the work areas of sharing the considered generating modes are combined with characteristics of the recuperative mode (Em \& Breido, 2012).

The analysis of characteristics showed the following:

1. the rigidness of mechanical characteristics in all range of speeds in the mode of a countercurrent is much higher, than in the recuperative mode that needs to be considered in case of creation automatic control systems of TED DC for sharing the modes of a recuperation and a countercurrent;

2. the working area of the recuperative mode is limited from rated speed to the angle of thyristor management $90^{\circ}$ down that is explained by pulse type of work and unilateral conductivity of the gate of the thyristor converter, at the same time the mode of recuperative braking can be realized only when EMF amplitude value of the engine exceeds EMF instant value of the power source;

3 . working range of an angle of thyristor management is in the recuperative mode $\alpha=90^{\circ} \div 130^{\circ}$, and for the mode of countercurrent $90^{\circ} \div 115^{\circ}$;

4. in all range of the considered capacities of electric motors the zone of inapplicability both recuperative and a countercurrent mode, limited from below to the maximum angle of management of the rectifier thyristor $110^{\circ} \div 120^{\circ}$ for the mode of countercurrent and from above the minimum angle of management of the inverter for the recuperative mode $90^{\circ}$ is found.

Besides, at a small EMF speed of the engine it has the continuous character, however origin of the discontinuous moment because of sign-variable impulse character of tension of an anchor is possible.

In this regard at small speeds there can be an unstable mode and, finally, there is a zone of inapplicability of a countercurrent characterized by unstable operation of the electric drive.

For elimination of this effect the technical solution can be offered (Byrka et al., 1991) which excludes unstable operation modes in the mode of a countercurrent also automatically provides a choice of the necessary generating mode. At the same time 
Breido, I.; Kaverin, V. \& Em, G.: The Research of the Adjustable Electric Drive of ... the non-reversing thyristor transformer in circuits of an anchor and the reverse thyristor driver in the drive winding are used.
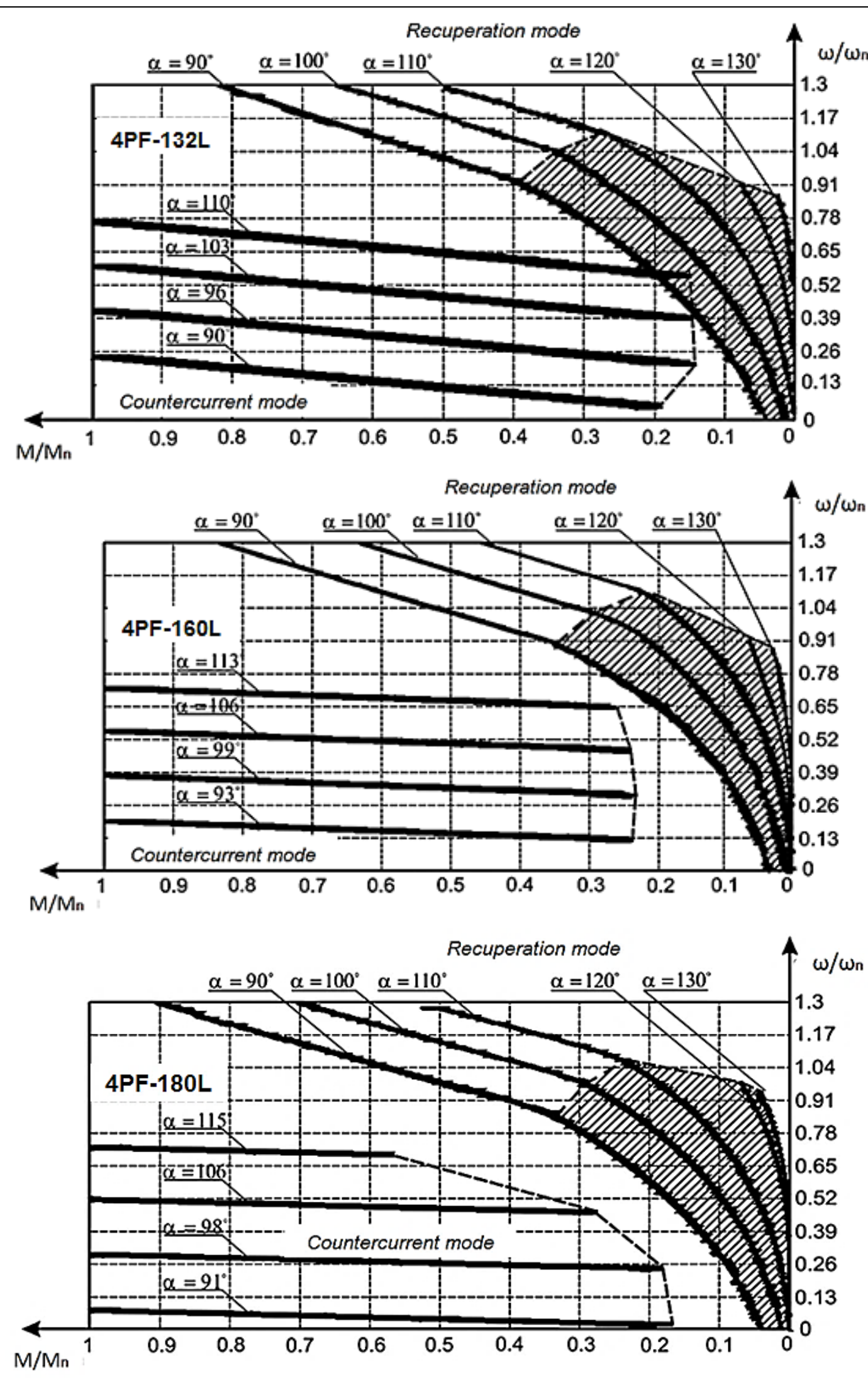

Fig. 1. Results of imitative experiments. 
Due to the above for implementation of the four-quadrant thyristor electric drive of a direct current sharing of the generating modes of countercurrent braking and with energy recuperation in a network is offered. At the same time, obviously, it is necessary to provide when lowering angular speed to boundary value the timely translation of the electric drive from a recuperative operation mode in the countercurrent mode. (Breido et al., 2013).

\section{The automatic control system of the emergency braking process}

In use mining machines and mechanisms after blackout the coal-mining combine or a working organ of the scraper pipeline continue to make progress due to stored kinetic energy. At the same time safety regulations impose strict requirements to length of a brake way of the capital mining equipment (Kaverin, 2000). In this regard it is necessary that brake mechanisms provided controlled braking after blackout that cannot be realized by means of the recuperative mode or countercurrent braking due to the lack of energy. The most known option of implementation of the modes of emergency braking in the electric drive is the method of dynamic braking with connection of the drive winding parallel or sequentially to an anchor. But this method is inapplicable in the electric drive regulated on speed as it is necessary to realize braking in a broad range of speed, and the applied to restriction of current of an anchor when braking from speeds, the close to nominal, current limiting resistor will not provide the necessary brake moment in the lower part of the range of speeds.

The technical solution on the basis of the dynamic braking system with the shunting diode connected parallel to the engine drive winding was developed for these conditions that allows to use the energy accumulated in the drive winding for implementation of the mode of emergency braking (Breido \& Kaverin, 1985).

As a result of it after blackout the electrical circuit of electromagnetic energy discharge is formed. The created circuit provides the step-by-step reduction of the accumulated energy to zero allowing to realize process of braking without additional sources of the electric power.

This decision is applicable also for the electric drive regulated on speed with engines of serial energization.

As for the adjustable electric drive it is required to provide steady braking in a broad range of speed, it is necessary to exclude the current limiting resistor from an anchor circuit, and restriction of the maximum value of current of an anchor can be provided by introduction of a time delay on short circuit of a circuit of an anchor. The proposed solution can be realized in the absence of additional sources of the electric power in a drive winding circuit, and a supply of the control unit is carried out by means of the low-power drive of energy as process of braking is short-time. The equivalent circuit of the electric drive in the mode of emergency braking taking into account the above is provided in a figure 2 . 


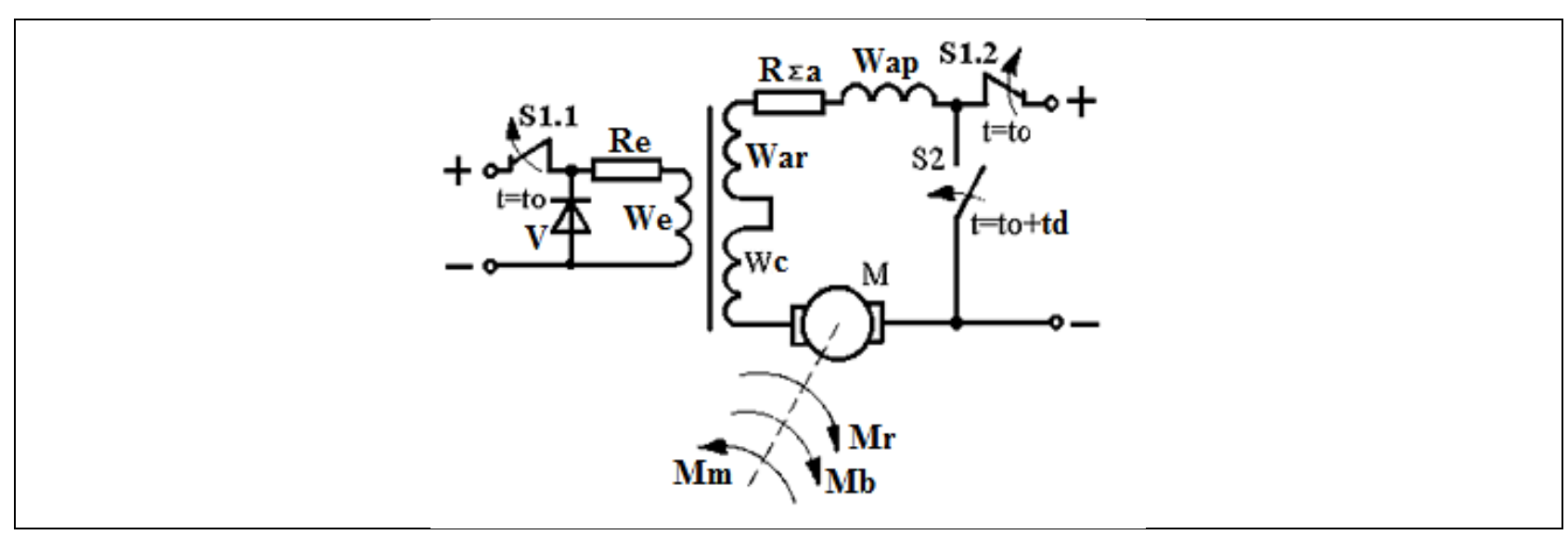

$\mathrm{U}_{\mathrm{B}}-$ tension on the drive winding; $\mathrm{i}_{\mathrm{e}}-$ excitation current; $\mathrm{i}_{\mathrm{a}}-$ armature current; $\mathrm{M}_{\mathrm{b}}-\mathrm{a}$ brake moment; $\mathrm{M}_{\mathrm{r}}$ - resistance moment; $\mathrm{M}_{\mathrm{m}}$ - a dynamic moment; $\mathrm{t}_{\mathrm{d}}$ - delay time; $\mathrm{R}_{\mathrm{e}}$ - resistance winding of excitation; $R_{\Sigma_{a}}$ - the total resistance of the armature circuit; $\mathrm{W}_{\mathrm{e}}-\mathrm{a}$ winding of excitation; $\mathrm{W}_{\mathrm{c}}-\mathrm{a}$ compensation winding; $\mathrm{W}_{\mathrm{ar}}-\mathrm{a}$ winding characterizing action of response of the armature; $\mathrm{W}_{\mathrm{ap}}-\mathrm{a}$ winding of additional poles.

Fig. 2. The equivalent circuit of the electric drive in the mode of emergency braking.

The offered diagram is developed taking into account the following assumptions:

- because of the magnetic conductor of the modern electro-motors is executed from laminated steel, influence of the eddy currents is insignificant, and it can be neglected;

- as in the engines used in adjustable electric drives, the magnetic conductor is executed from magnet-soft materials, the residual flow is very small, and it can also be neglected.

Generalized direct current motor containing a compensation winding and a winding of additional poles were used in the equivalent circuit. This diagram describes the electro-motors of serial and independent energization with power up to $200 \mathrm{~kW}$ used in the considered classes of machines and mechanisms.

Influence of the magnetic communication between an anchor contour and the drive winding is considered by introduction to the equivalent circuit of an additional winding $\mathrm{W}_{\mathrm{ap}}$ which action is equivalent to the degaussing effect of the anchor.

It is expedient to consider transformation of energy only from an anchor circuit in energization circuit as the power consumption in a circuit of energization, it is less than $10 \%$ of energy circuit of an anchor (Breido et al., 2013).

Sudden blackout is imitated by breaking of keys S1.1 and S1.2, and process control of braking is exercised by means of short circuit of a key S2 with an adjustable exposure of time. Process of braking arises with the advent of an anchor circuit current after switching of a key S1.

The processes proceeding in the engine when braking are described by the following system of differential equations in the relative units (Kaverin, 2000): 


$$
\begin{aligned}
& 0=i_{\mathrm{e}}^{*}+\mathrm{T}_{1} \frac{\mathrm{dF}_{\Sigma}^{*}}{\mathrm{dt}} \\
& \mathrm{F}_{\mathrm{c}}^{*}=\mathrm{F}_{\mathrm{fw}}^{*}-\mathrm{F}_{\mathrm{ra}}^{*}+\mathrm{F}_{\mathrm{cw}}^{*} \\
& \mathrm{~F}_{\mathrm{fw}}^{*}=\mathrm{f}_{1}^{*}\left(i_{\mathrm{e}}^{*}\right) \\
& \mathrm{F}_{\mathrm{ra}}^{*}=\mathrm{f}_{2}^{*}\left(i_{\mathrm{a}}^{*}\right) \\
& \mathrm{F}_{\mathrm{cw}}^{*}=\mathrm{f}_{3}^{*}\left(i_{\mathrm{a}}^{*}\right) \\
& \omega^{*} \mathrm{~F}_{\Sigma}^{*}=\rho_{\mathrm{a}}\left(\mathrm{i}_{\mathrm{a}}^{*}+\mathrm{T}_{\mathrm{a}} \frac{\mathrm{di}_{\mathrm{a}}}{\mathrm{dt}}\right) \\
& -\mathrm{T}_{\mathrm{m}} \frac{\mathrm{d} \omega^{*}}{\mathrm{dt}}=\mathrm{M}_{\mathrm{b}}^{*}+\mathrm{M}_{\mathrm{r}}^{*} \\
& \mathrm{M}_{\mathrm{b}}^{*}=\mathrm{i}_{\mathrm{a}}^{*} \mathrm{~F}_{\Sigma}^{*}
\end{aligned}
$$

where:

$$
\begin{aligned}
& \mathrm{T}_{1}=\frac{2 \mathrm{PW}_{\mathrm{fw}}}{\mathrm{R}_{\mathrm{fw}} \mathrm{i}_{\mathrm{nc}}} ; \mathrm{f}_{1}^{*}=\mathrm{f}_{1} \frac{\mathrm{I}_{\mathrm{n}}}{\mathrm{F}_{\mathrm{n}}} ; \mathrm{f}_{2}^{*}=\mathrm{f}_{2} \frac{\mathrm{I}_{\mathrm{n}}}{\mathrm{F}_{\mathrm{n}}} ; \mathrm{f}_{3}^{*}=\mathrm{f}_{3} \frac{\mathrm{I}_{\mathrm{n}}}{\mathrm{F}_{\mathrm{n}}} ; \mathrm{T}_{\mathrm{a}}=\frac{\mathrm{L}_{\mathrm{a}}}{\mathrm{R}_{\mathrm{a}}} ; \mathrm{T}_{\mathrm{m}}=\frac{J \omega_{\mathrm{n}}}{\mathrm{M}_{\mathrm{n}}} ; \rho_{\mathrm{a}}=\frac{\mathrm{R}_{\mathrm{a}} \mathrm{I}_{\mathrm{n}}}{\mathrm{E}_{\mathrm{b}}} ; \\
& \mathrm{i}_{\mathrm{e}}^{*}=\frac{\mathrm{i}_{\mathrm{e}}}{\mathrm{I}_{\mathrm{ne}}} ; \mathrm{i}_{\mathrm{a}}^{*}=\frac{\mathrm{i}_{\mathrm{a}}}{\mathrm{I}_{\mathrm{na}}} ; \mathrm{F}_{\Sigma}^{*}=\frac{\mathrm{F}_{\Sigma}}{\mathrm{F}_{\mathrm{n}}} ; \mathrm{F}_{\mathrm{ra}}^{*}=\frac{\mathrm{F}_{\mathrm{ra}}}{\mathrm{F}_{\mathrm{n}}} ; \mathrm{F}_{\mathrm{e}}^{*}=\frac{\mathrm{F}_{\mathrm{e}}}{\mathrm{F}_{\mathrm{n}}} ; \mathrm{F}_{\mathrm{cw}}^{*}=\frac{\mathrm{F}_{\mathrm{cw}}}{\mathrm{F}_{\mathrm{n}}} ; \omega^{*}=\frac{\omega}{\omega_{\mathrm{n}}} ; \mathrm{M}_{\mathrm{b}}^{*}=\frac{\mathrm{M}_{\mathrm{b}}}{\mathrm{M}_{\mathrm{n}}} ; \\
& \mathrm{M}_{\mathrm{r}}^{*}=\frac{\mathrm{M}_{\mathrm{r}}}{\mathrm{M}_{\mathrm{n}}} ; \mathrm{E}_{\mathrm{b}}=\mathrm{CF}_{\mathrm{n}} \omega_{\mathrm{n}} ;
\end{aligned}
$$

$\mathrm{F}_{\Sigma}-$ a resultant magnetic flux;

$\mathrm{F}_{\mathrm{fw}}$ - a magnetic flux from the drive winding;

$\mathrm{F}_{\mathrm{ra}}$ - a magnetic flux from an anchor response;

$\mathrm{F}_{\mathrm{cw}}$ - a magnetic flux from a compensation winding electromotor;

$\omega$ - angular speed of the engine;

$2 \mathrm{P}$ - number of couples of poles;

$\mathrm{W}_{\mathrm{e}}$ - number of rounds of one winding electromotor of the principal poles;

$\mathrm{C}-\mathrm{a}$ constructive constant of the electromotor;

$\mathrm{f}_{1}$-dependence of a component of magnetic flux from power of the winding electromotor;

$\mathrm{f}_{2}$ - dependence of a component of a magnetic flux of response of an anchor on anchor current;

$\mathrm{f}_{3}$ - dependence of a component of a magnetic flux of a compensation winding on anchor current;

$\mathrm{J}$ - electromotor inertia moment;

$I_{n a}, I_{n e}, F_{n}, \omega_{n},-$ nominal parameters of an anchor current, a current of the drive winding, a magnetic flux, angular frequency of an anchor rotation and the moment of the electromotor, respectively. 
Breido, I.; Kaverin, V. \& Em, G.: The Research of the Adjustable Electric Drive of ...

The research of transient phenomena of the electric drive in the mode of emergency braking was conducted by MIK AL simulation modeling. (Breido et al., 2010).

Solving the equation of the mechanical equilibrium (7) concerning the value of the brake way, we receive the following expression:

$$
\mathrm{S}_{0}=\mathrm{k} \int_{0}^{\mathrm{t}_{1}}\left[\omega_{0}^{*}-\frac{1}{\mathrm{~T}_{\mathrm{M}}} \int_{0}^{\mathrm{t}_{1}}\left(\mathrm{M}_{\mathrm{T}}^{*}+\mathrm{M}_{\mathrm{C}}^{*}\right) \mathrm{dt}\right] \mathrm{dt}
$$

where:

$\mathrm{S}_{0}$ - the size of a brake way;

$\mathrm{k}$ - the coefficient characterized by nominal rate of angular speed, transfer number of a reducer and design data of working body;

$\mathrm{t}_{1}$ - braking time.

It is obvious that, with increase in the brake moment the brake way is reduced. Thus, for the purpose of reduction of a brake way it is necessary to support the brake moment at the level of the most admissible value.

$$
t_{T}=T_{M} \int_{\omega_{0}}^{0}\left[\frac{1}{-M_{T}^{*}-M_{C}^{*}}\right] d \omega
$$

Similarly, for the purpose of time minimization of braking it is necessary to provide the most admissible brake moment.

In the analyzed scheme of the electric drive, in the mode of the operated braking, there is no current-limiting resistor in a circuit therefore practically in all the range of change of a magnetic flux it is necessary to limit anchor current.

At two-zonal regulation of the electric drive that takes place in coal-mining machines and load-lifting mechanisms, the speed of the electric drive can exceed nominal size. It is possible to organize braking for speed above nominal taking into account restriction of switching loading of collector and brush group.

Thus, for realization of the brake mode it is necessary to define boundary areas of initial value of angular speed at which it is necessary to pass from restriction of switching loading of collector and brush group to restriction the current of an anchor and further to restriction an electromagnetic moment.

Thus, at value of angular speed more $\omega_{2}$, it is necessary to limit anchor current at the level of the most admissible value. At the same time for power setting in which angular speed exceeds nominal rate, it is necessary to carry out restriction of switching loading of collector and brush group.

For definition of quantitative characteristics of the mechanical loadings arising in the course of emergency braking it is necessary to calculate the size of the maximum brake moment in all range of initial values of angular speed.

Certain dependences of the maximum value of the brake moment for various types of electric motors are presented in the figure 3. 
Apparently from the figure 3, with reduction of initial value of angular speed for all types of electric motors the maximum value of the brake moment for all types of electric motors increases. For the decrease purpose in dynamic loading of the electric drive it is expedient to introduce restriction of the electromagnetic moment on this site. This problem can be solved having applied linear approximation of nonlinear dependence of delay time on initial value of speed on the site of restriction an anchor current. For the simplification purpose of a control system realization of emergency braking process and for reduction of dynamic loading of the electric drive it is expedient to approximate dependence of time of a delay as initial value of angular speed at $\omega_{0} \leq 1$ straight line; in the figure 3 it is shown by a dashed line.

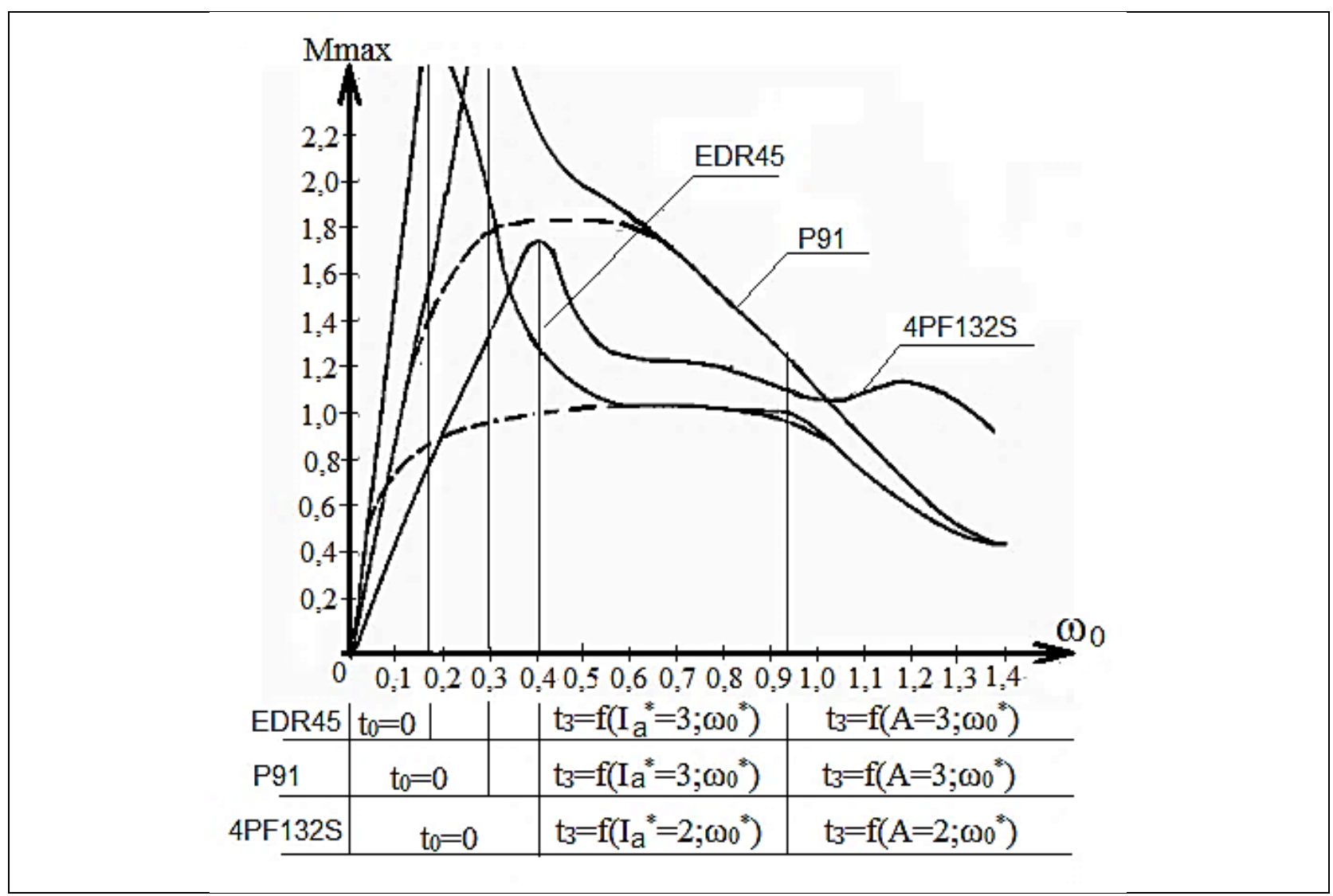

Fig. 3. Dependence of the maximum value of the brake moment of the electric drive in the emergency braking mode.

Thus, changing delay time for the corresponding intervals of angular speed, control of emergency braking so that at the same time the maximum value of current of an anchor does not exceed admissible value, and at a speed more nominal rate requirements for switching in collector and brush group are fulfilled. The maximum value of the brake moment for the electric motor 4PF132S in all range of change of initial value of angular speed shouldn't exceed 1,2 nominal rates. For Electric motors series EDR the maximum value of the brake moment in all range of angular speed of initial value of angular speed shall not exceed nominal rate, and the maximum value P91 of the brake moment of the electric motor is less than 1,8 .

Pilot studies of the electric drive in the mode of the operated braking were conducted at stands with electric motors of various systems of energization: EDR45 
Breido, I.; Kaverin, V. \& Em, G.: The Research of the Adjustable Electric Drive of ...

(non-compensated engine of consecutive energization); P91 (non-compensated engine of independent energization); 4PF132S (the compensated engine of independent energization) (Kaverin, 2000).

Assessment of the mathematical model adequacy was carried out in two stages. At first the accuracy of a curve approximation of magnetization was estimated, and the adequacy of all model with use of the transition processes received theoretically and experimentally was checked then.

In pilot studies process of electric motors with various types of energization in the mode of emergency braking entry conditions of angular speed and a magnetic flux and also delay size on shortening circuits of an anchor have been changed.

The adequacy of mathematical model of the management object was estimated by comparison of instant values of the corresponding output coordinates of the mathematical model and physical model of an object.

The numerical value of a brake way depends on parameters of a reducer and working body, in this regard for quantitative assessment of size of a brake way the parameter proportional to the size of a brake way - an integrated indicator of angular speed has been chosen.

$$
\varphi=\int_{0}^{\mathrm{t}} \omega(\mathrm{t}) \mathrm{dt}
$$

As a result of comparison of the corresponding transition processes received theoretically and experimentally, a mathematical model error of the engine in the mode of emergency braking is defined.

Numerical values of an error of the maximum value of current of an anchor and integrated value of angular speed for various values of entry conditions and time of a delay are presented in table 1 .

\begin{tabular}{|l|c|c|c|}
\hline \multirow{2}{*}{ Parameter } & \multicolumn{3}{|c|}{ Electromotor type } \\
\cline { 2 - 4 } & 4PF132S & P91 & EDR45 \\
\hline Integrated indicator of angular speed & $\leq 8 \%$ & $\leq 8 \%$ & $\leq 1 \%$ \\
\hline Maximum value of an anchor current & $\leq 5 \%$ & $\leq 4 \%$ & $\leq 3 \%$ \\
\hline
\end{tabular}

Tab. 1. Numerical values of the mathematical modeling error of direct current motors in the emergency braking mode.

It is established that the mathematical model describes the processes proceeding in the drive in the emergency braking mode with a sufficient accuracy for synthesis of automatic control systems of emergency braking process by comparison of transition processes of the corresponding coordinates. Results of pilot studies have shown that the mathematical modeling error of the physical processes proceeding in the electric motor in the modes of the operated braking did not exceed $9 \%$. Despite a number of the accepted assumptions, the dynamic model, generally reflects the nature 
of the transition processes proceeding in the electric motor in the dynamic braking mode at change of initial conditions in range of 1:10.

The maximum values of an anchor current, the brake moment and integral of angular speed for the corresponding initial values of speed are presented in table 2 .

\begin{tabular}{|l|c|c|c|}
\hline$\omega_{0}^{*}$ & 1,37 & 0,84 & 0,167 \\
\hline $\mathrm{i}^{*}{ }_{\mathrm{a} \text { max }}$ & 2,4 & 2,6 & 1,5 \\
\hline$\varphi($ radian $)$ & 14,4 & 7,98 & 2,68 \\
\hline $\mathrm{M}_{\mathrm{b} \max }^{*}$ & 0,84 & 1,22 & 0,97 \\
\hline
\end{tabular}

Tab. 2. Values $\varphi, \mathrm{M}_{\mathrm{b} \max }^{*}, \mathrm{i}_{\mathrm{a} \text { max }}^{*}$ for the electric drive with the engine 4PF132S in the mode of emergency braking.

In the pilot studies process it is established that for the compensated electric motor with independent energization, steady braking at change of initial value of angular speed in range of 1:10 is provided. During braking the full discharge of the kinetic energy reserved in the swing mass of the electric motor is carried out. The maximum value of the brake moment did not exceed 1,3 Mn.

Results of pilot studies have shown that for 4PF compensated series, electric motors at the initial value of angular speed exceeding nominal rate the $100 \%$ discharge of kinetic energy is carried out. It is explained by overcompensation of magnetic system of the engine at small values of a magnetic flux component from energization winding current. In this regard the size of the maximum value of the brake moment decreases slightly (Kaverin, 2000).

Reduction of the kinetic energy discharge reserved in swing masses in comparison with the compensated electric motors is observed at non-compensated electric motors during the full discharge of electromagnetic energy in a contour of a winding energization.

Significant effect on the brake moment decrease in the time period when an anchor current has reached the maximum value and begun to decrease, transformation of energy from an anchor contour in an energization winding contour exerts impact. This effect is dramatically shown at the series electric motors because of design features and parameters of a winding energization.

Tests of a subsystem of emergency braking were carried out at the stand for rating the dynamic characteristics of the electric drive of the scraper conveyor.

The values of brake ways of the conveyor stop after blackout with emergency braking and without him for the corresponding initial values of angular speed have been defined for determination of a subsystem efficiency of emergency braking on the basis of experimentally received transition processes, and transition processes with the equations use of mathematical model are constructed.

Results of pilot studies are presented in figure 4.

The moment of resistance of the conveyor working body of given to an electric motor shaft for a free run out case did not exceed 0,3 values of the nominal electromagnetic moment. Length of a free run out (at the maximum initial value of 
Breido, I.; Kaverin, V. \& Em, G.: The Research of the Adjustable Electric Drive of ... speed of the conveyor working body $\mathrm{Vvo}=0,82 \mathrm{~m} / \mathrm{s}$ ) was $0,76 \mathrm{~m}$ that is $52 \%$ more than the value regulated by requirements of safety measures.

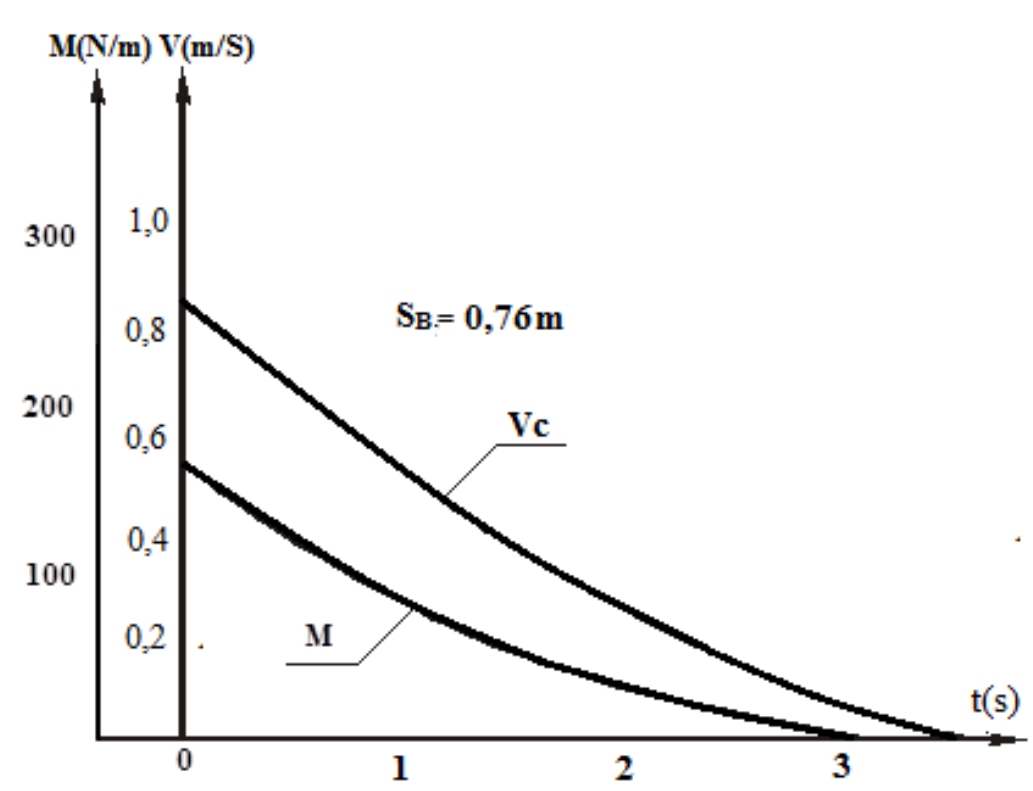

a)

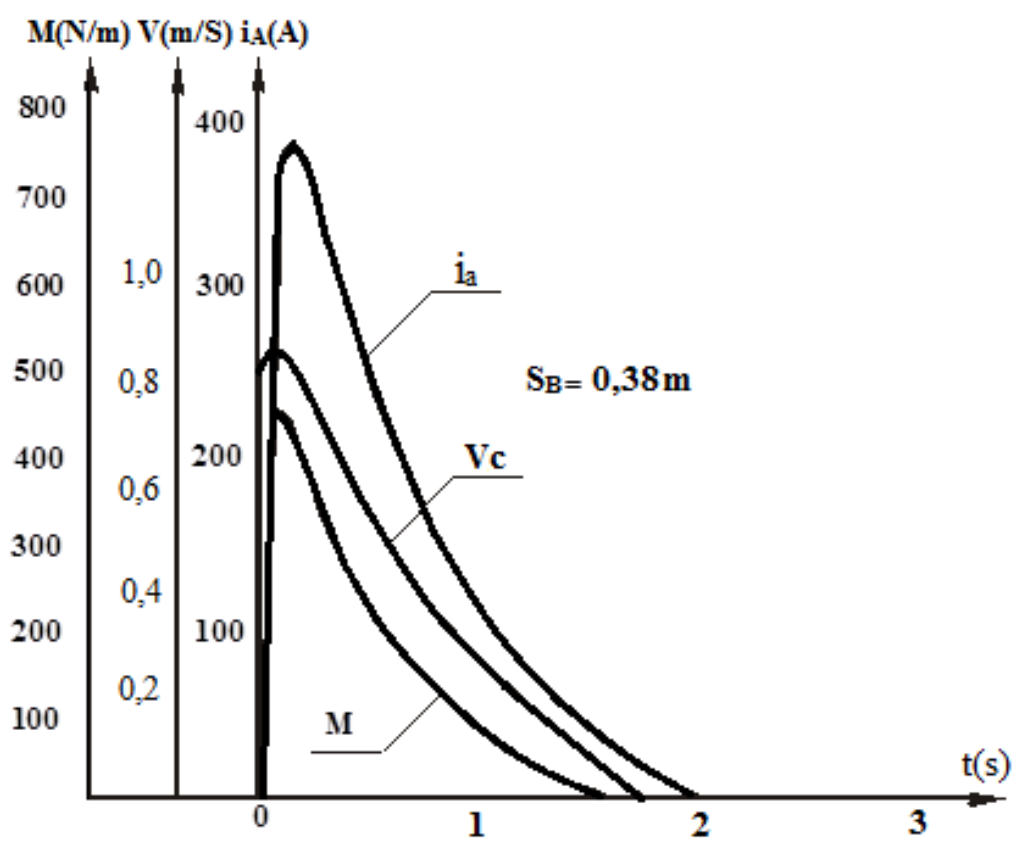

b)

Fig. 4. Transition processes of the electric drive of the conveyor in the mode of emergency braking $\mathrm{Vv} 0=0,82 \mathrm{~m} / \mathrm{s}$.

Use of system of emergency braking reduces length of a free run out to $0,38 \mathrm{~m}$, at the same time the maximum value of the brake moment taking into account the given moment of resistance does not exceed 1,3 nominal rates of the electromagnetic moment.

Thus, at the maximum speed use of emergency braking system has allowed to reduce a brake way twice. At further reduction of initial speed value of conveyor working body the size of a brake way in relation to free run out decreased not less, 
than twice at insignificant decrease in the maximum value of the brake moment. The maximum value of an anchor current during braking did not exceed triple nominal rate (Kaverin, 2000).

\section{Conclusion}

As a result of the executed researches of the generating modes of the thyristor electric drive with sign-variable the moment of loading it is established that the mode of recuperative braking can be realized only at great and average values of the electric motor speed. In lower parts of speeds range where the current-limiting resistor is not required, the most effective is back connection.

Technical solution which automatically provides the choice of the necessary generating mode is proposed: recuperation or back connection.

Theoretical researches of the modes of emergency braking connected with blackout are executed. Technical solution on the basis of the system of dynamic braking with the shunting diode connected parallel to a winding of energization of the engine is developed that allows to use the energy reserved in an energization winding for realization of the mode of emergency braking. This decision is applicable also for the electric drive adjusted on speed with engines of consecutive energization.

The current-limiting resistor is excluded from a circuit of an anchor, and restriction of the maximum value of current of an anchor is provided by introduction of a delay on short circuit of an anchor circuit.

Mathematical models of the electric drive in the modes of emergency braking taking into account transformation of energy in an energization winding circuit from an anchor circuit are developed. The main criteria of work of system of emergency braking are developed.

Pilot studies of emergency braking system on the conveyor are executed. Reduction of a brake way is provided twice at energy shutdown at the maximum speed. At a small speed of working body of the conveyor the size of a brake way in relation to free run out decreased not less, than twice at insignificant decrease in the maximum value of the brake moment. The maximum value of an anchor current during braking did not exceed triple nominal rate.

Results of the executed researches and the proposed technical solutions have been applied in experimental and prototype samples of thyristor electric drives of coal-mining combines and conveyors supplying to coal mines. Their areas can be expanded for a wide class of cars and mechanisms with the sign-variable moment of loading, that is in cranes, excavators, hoist engines, etc. with regulated electric drive.

Further, similar researches for transistor electric drives on the basis of widthimpulse converters is supposed.

\section{References}

Bhadra, Sailendra N.; De, Nisit K. \& Chattopadhyay, A. (2017). Regenerative Braking Performance Analysis of a Thyristor-Chopper Controlled DC Series Motor, Available from: https://www.researchgate.net/publication/3475857 - Indian Institute 
Breido, I.; Kaverin, V. \& Em, G.: The Research of the Adjustable Electric Drive of ...

of Engineering Science and Technology, Shibpur, Accessed: 2017-06-23

Breido, I. \& Kaverin, V. (1985). The device for emergency braking of the electric drive of a direct current(s), Copyright certificate for the invention No.1198719 USSR, Bulletin No.46, 1985-12-15

Breido, I. (1993). Influence of real service conditions on structure and parameters of the operated electric drives of non-stationary mining machines, Higher education institutions. Mining magazine, No.8 August 1993, pp. 116-119, ISSN: 0536-1028

Breido, I.; Feshin, B.; Kaverin, V. \& Em, G. (2010). Methodology of imitating modeling of the semiconductor electric drive of a direct current, Driving equipment, No.5 October 2010, pp. 44-48, ISSN: 2077-6411

Breido, I. \& Em, G. (2011). The generating modes research of the thyristor electric drive of mining machines. Mining equipment and electro-mechanics., No.3 March 2011, pp. 25-31, ISSN: 1816-4528

Breido, I.; Kaverin, V. \& Em, G. (2013). Nonlinear four-quadrant thyristor electric drive of a direct current, Publishing house of Karaganda state technical university, ISBN: 978-601-296-507-0, Karaganda, Kazakstan

Byrka, V; Breido, I.; Peters, I. \& Tomilin, N. (1991). Reversive electric drive, Copyright certificate for the invention No.1667213 USSR, Bulletin No.28, 1991-0730

Daware, K. (2014). Electric Braking Of DC Motors, Available from: http://www.electricaleasy.com/2014/01/electric-braking-of-dc-otors.html. Accessed: 2017-06-24

Em, G. \& Breido, I. (2012). Thyristor electric drive of a direct current of mining machines: Influence of pulse type of work of the power converter on properties of the thyristor electric drive of a direct current, LAP LAMBERT Academic Publishing GmbH \& Co., ISBN: 978-3-659-16326-5, Saarbrücken, Germany

Em, G. (2013). Analysis of generating operating modes and circuitry solutions of power converters of the thyristor electric drive of a direct current of mining machines and mechanisms, Higher education institutions. Electro-mechanics, No.3, June 2013, pp. 57-60, ISSN: 0136-3360,

Kaverin, V. (2000). Pilot study of the electric drive of a direct current in the mode of the operated dynamic braking, Works of the university, No.3, March 2000, pp. 18-19, ISSN: 0136-3360

Rashid, Muhammad H. (2017). Regenerative Characteristics of DC Chopper Controlled Series Motors, Available from: https://www.researchgate.net/publication/ 3156037. Accessed: 2017-06-24

Sen, P. (1981). Thyristor DC Drives, John Wiley \& Sons, ISBN: 978-0-471-06070-3, New York

Subramanyam, V. (1987). Thyristor Control of Electric Drives, Tata McGraw-Hill, ISBN: 0-0746-0341-8, New Delhi 